\title{
Comparing random and regular diketopyrrolopyrrole- bithiophene-thienopyrrolodione terpolymers for organic photovoltaics
}

\author{
Citation for published version (APA): \\ Hendriks, K. H., Heintges, G. H. L., Wienk, M. M., \& Janssen, R. A. J. (2014). Comparing random and regular \\ diketopyrrolopyrrole-bithiophene-thienopyrrolodione terpolymers for organic photovoltaics. Journal of Materials \\ Chemistry A, 2, 17899-17905. https://doi.org/10.1039/C4TA04118F
}

DOI:

10.1039/C4TA04118F

Document status and date:

Published: 01/01/2014

\section{Document Version:}

Publisher's PDF, also known as Version of Record (includes final page, issue and volume numbers)

\section{Please check the document version of this publication:}

- A submitted manuscript is the version of the article upon submission and before peer-review. There can be important differences between the submitted version and the official published version of record. People interested in the research are advised to contact the author for the final version of the publication, or visit the DOI to the publisher's website.

- The final author version and the galley proof are versions of the publication after peer review.

- The final published version features the final layout of the paper including the volume, issue and page numbers.

Link to publication

\footnotetext{
General rights

- You may freely distribute the URL identifying the publication in the public portal. follow below link for the End User Agreement:

www.tue.nl/taverne

\section{Take down policy}

If you believe that this document breaches copyright please contact us at:

openaccess@tue.nl

providing details and we will investigate your claim.
}

Copyright and moral rights for the publications made accessible in the public portal are retained by the authors and/or other copyright owners and it is a condition of accessing publications that users recognise and abide by the legal requirements associated with these rights.

- Users may download and print one copy of any publication from the public portal for the purpose of private study or research.

- You may not further distribute the material or use it for any profit-making activity or commercial gain

If the publication is distributed under the terms of Article $25 \mathrm{fa}$ of the Dutch Copyright Act, indicated by the "Taverne" license above, please 


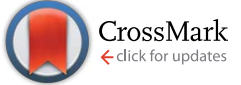

Cite this: J. Mater. Chem. A, 2014, 2, 17899

Received 9th August 2014

Accepted 11th September 2014

DOI: $10.1039 / c 4 t a 04118 f$

www.rsc.org/MaterialsA

\section{Comparing random and regular diketopyrrolopyrrole-bithiophene- thienopyrrolodione terpolymers for organic photovoltaics $\uparrow$}

\begin{abstract}
Koen H. Hendriks, Gaël H. L. Heintges, Martijn M. Wienk and René A. J. Janssen*
Isomeric random and regular alternating $\pi$-conjugated terpolymers comprising diketopyrrolopyrrole (DPP), thienopyrrolodione (TPD), and bithiophene (2T) were synthesized to study the effect of the sequential distribution of monomeric units on the semiconducting properties. The optical and electrochemical properties and the performance in photovoltaic cells of the random and regular terpolymers are found to be significantly different. DPP2T-rich sections in the random terpolymer cause higher HOMO and deeper LUMO energy levels and a smaller optical band gap compared to the regular terpolymer. The randomization of DPP and TPD units along the chain has a negative effect on the photovoltaic performance, resulting in power conversion efficiencies of merely $1.0 \%$ for the random terpolymer while a more favorable efficiency of $5.3 \%$ is obtained for the regular terpolymer when combined with a fullerene acceptor.
\end{abstract}

\section{Introduction}

Bulk heterojunction polymer/fullerene organic solar cells rely on the combination of a strong light-absorbing polymer that is intimately blended with a fullerene derivative. The design of new conjugated polymers for this application often combines electron rich and electron poor moieties in an alternating pushpull polymer chain architecture. This enables control over the optical band gap and energy levels of the material by varying the nature of these moieties. Two acceptor groups that have been investigated extensively are diketopyrrolopyrrole (DPP) and thienopyrrolodione (TPD). Owing to its electron deficiency, DPP is known for providing access to small band gap polymers with high efficiencies in photovoltaic devices and ambipolar charge transport in field-effect transistors. ${ }^{1-6}$ TPD is slightly less electron deficient, which results in wide to medium band gap materials. ${ }^{7-10}$ Traditionally, semiconducting copolymers with a push-pull configuration only use the combination of one donor and one acceptor. Recently, terpolymer design strategies have been explored as a tool to control the physical properties of push-pull polymers. In this approach, two electron rich (or electron poor) building blocks are combined with one electron poor (or electron rich) building block. ${ }^{2,11-15}$ Incorporation of the

Molecular Materials and Nanosystems, Institute for Complex Molecular Systems, Eindhoven University of Technology, P.O. Box 513, 5600 MB Eindhoven, The Netherland. E-mail: r.a.j.janssen@tue.nl

$\uparrow$ Electronic supplementary information (ESI) available: Additional figures and the detailed synthesis and analysis of the monomers, reg-PDPP/TPDalt2T and ran-PDPP/TPDalt2T are described. See DOI: 10.1039/c4ta04118f different co-monomers in the polymer can be achieved in a regular or a (semi)random fashion.

One of the principal reasons for using multiple components in the synthesis of semi-conducting polymers is that it can lead to broadening of their absorption spectra, which can be beneficial for the harvesting of photons in a photovoltaic cell. ${ }^{16,17}$ Another opportunity is to tune the molecular packing by introducing components that favor $\pi-\pi$ stacking. ${ }^{18,19}$ The different electron affinities of the components also allows to effectively tune the HOMO and LUMO energy levels. ${ }^{20}$ Especially the physical properties of random terpolymers can be easily tuned by simply varying the initial stoichiometry of monomers in the polymerization reaction. ${ }^{21}$ While for regular alternating terpolymers the frontier orbitals are likely to be extended over all different units, resulting in sharp absorption bands and a defined HOMO and LUMO, ${ }^{2}$ in random terpolymers the various sections with different chemical composition can lead to broadening of the energy levels and possible formation of trapsites. ${ }^{\mathbf{1 4}}$ This is however highly dependent on the electronic nature of the building blocks that are studied and therefore does not necessarily need to undermine the photovoltaic performance. In fact, several groups have reported random terpolymers that outperform both corresponding co-polymers. ${ }^{11,22,23}$ More specific, random terpolymers of DPP and TPD alternating with oligothiophenes, ${ }^{13}$ benzodithiophene ${ }^{\mathbf{1 4}}$ or benzotrithiophene ${ }^{24}$ have been shown to give good photovoltaic performance with high short-circuit currents as a result of spectral broadening. On the other hand, some systems have been reported were regular alternating terpolymers show higher 
performance compared to their random counterparts. ${ }^{25-27}$ Therefore no clear design rules that are in favor of random or regular terpolymers appear to be present at the moment.

While it is common practice to compare the physical properties and photovoltaic performance of terpolymers to their corresponding parent co-polymers, reports on the direct comparison between regular and random alternating terpolymers are scarce. Sun et al. described the differences between a regular and random terpolymer of isoindigo and quinoxaline alternating with thiophene. ${ }^{26}$ In this particular case, the optoelectronic properties of both polymers were exclusively determined by the isoindigo part of the polymer because the absorption spectra showed minimal differences between the two variants and the HOMO and LUMO energy levels were identical. Braunecker et al. reported on oligo-benzodithiophenes alternating with thienoisoindolodione in a random or regular fashion where they found a higher photovoltaic performance for the random materials. ${ }^{28}$ On the other hand, Deng et al. found that for a system based on phenanthrocarbazole and bezothiadiazole alternating with thiophene, the regular alternating polymer had a higher performance. ${ }^{27}$

Here we describe the synthesis and comparison of isomeric random and regular terpolymers comprising both DPP and TPD alternating with bithiophene (2T). The significantly different electron deficiencies of DPP and TPD are expected to give rise to panchromatic absorption. Further, by using T-DPP-T and TTPD-T monomers, with identical end groups, conditions for random rather than semi-random polymerization are enhanced. In the random material we find a broadening of the absorption spectra towards the red owing to -T-DPP-T-T-DPP-Trich segments in the backbone. These segments effectively increase the HOMO and decrease the LUMO energy levels compared to the regular isomer. As a result, the random terpolymer displays a significantly lower efficiency in photovoltaic devices compared to the regular variant.

\section{Results and discussion}

Two isomeric PDPP/TPDalt2T terpolymers were synthesized, differing only in the monomer sequence within the polymer backbone (Scheme 1). Both polymers contain equal numbers of DPP and TPD acceptors alternating with $2 \mathrm{~T}$ as donor but differ in their regular (D-A1-D-A2 $)_{n}$ or random $\left[(\mathrm{D}-\mathrm{A} 1)_{n}-(\mathrm{D}-\mathrm{A} 2)_{m}\right]$ alternating structure along the chain. The random terpolymer will inherently contain domains that are rich in DPP2T or in TPD2T, next to alternating DPP2T-TPD2T segments. The regular alternating terpolymer (reg-PDPP/TPDalt2T) was synthesized via a Suzuki polycondensation of 2,5-bis(2-hexyldecyl)-3,6-bis(5(4,4,5,5-tetramethyl-1,3,2-dioxaborolan-2-yl)thiophen-2-yl)pyrrolo[3,4-c]pyrrole-1,4(2H,5H)-dione and 1,3-bis(5-bromothiophen-2-yl)-5-(heptadecan-9-yl)-4H-thieno[3,4-c]pyrrole-4,6(5H)dione. The reaction initiated already at room temperature and proceeded very quickly, yielding reg-PDPP/TPDalt2T with an average molecular weight of $M_{\mathrm{n}}=50.0 \mathrm{~kg} \mathrm{~mol}^{-1}$ and $M_{\mathrm{w}}=137$ $\mathrm{kg} \mathrm{mol}^{-1}$. The random terpolymer (ran-PDPP/TPDalt2T) was synthesized using a Yamamoto homo-coupling polymerization from equivalent amounts of 3,6-bis(5-bromothiophen-2-yl)-2,5bis(2-hexyldecyl)pyrrolo[3,4-c]pyrrole-1,4(2H,5H)-dione and 1,3bis(5-bromothiophen-2-yl)-5-(heptadecan-9-yl)-4H-thieno[3,4-c]pyrrole-4,6(5H)-dione. ran-PDPP/TPDalt2T has $M_{\mathrm{n}}=34.6 \mathrm{~kg}$ $\mathrm{mol}^{-1}$ and $M_{\mathrm{w}}=116 \mathrm{~kg} \mathrm{~mol}{ }^{-1}$. The stoichiometric incorporation of monomers in ran-PDPP/TPDalt2T was verified via NMR spectroscopy and found to be identical to reg-PDPP/TPDalt2T (ESI, Fig. S1†). The corresponding copolymers PDPP2T and PTPD2T were also synthesized for comparison. PDPP2T was obtained from a Yamamoto polymerization of 3,6-bis(5-bromothiophen-2-yl)-2,5-bis(2-hexyldecyl)pyrrolo[3,4-c]pyrrole$1,4(2 H, 5 H)$-dione with a $M_{\mathrm{n}}=85 \mathrm{~kg} \mathrm{~mol}^{-1} \cdot{ }^{29}$ PTPD2T was synthesized in a similar fashion from 1,3-bis(5-bromothiophen2-yl)-5-(heptadecan-9-yl)-4H-thieno[3,4-c]pyrrole-4,6(5H)-dione. This polymer proved to be largely insoluble and could not be properly characterized; therefore it was omitted for this study. The physical properties of the new terpolymers and PDPP2T are summarized in Table 1.

Fig. 1 shows the absorption spectra of solutions of the two isomeric polymers. For the regular PDPP/TPDalt2T terpolymer a sharp onset of the electronic transitions and a narrow band are observed. In contrast, the random PDPP/TPDalt2T isomer shows an onset at lower energies, a significant broadening of the spectrum, and the appearance of multiple shoulders. Similar differences are observed in thin films (ESI, Fig. S2 $\dagger$ ). We conjecture that longer segments enriched in TPD or DPP electron deficient moieties lead to local differences in the HOMO and LUMO energy levels along the chain of the random
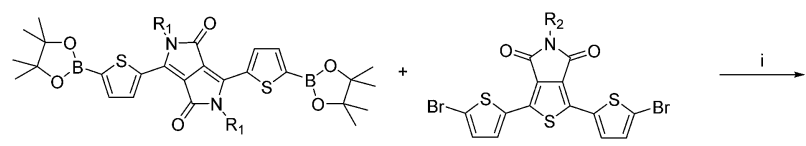

$R_{1}=2$-hexyldecyl
$R_{2}=1$-octylnonyl
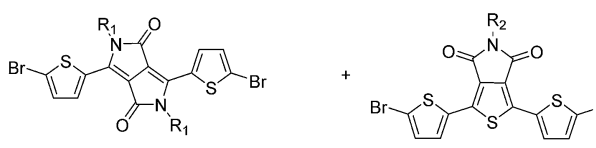
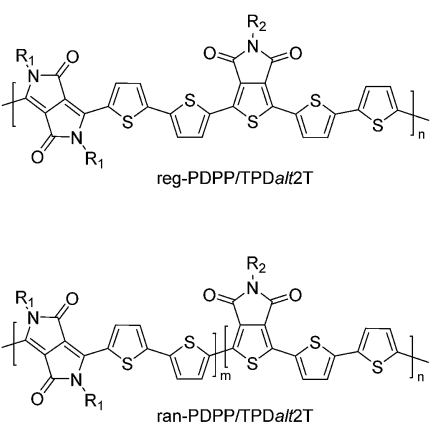

Scheme 1 Polymerization of regular reg-PDPP/TPDalt2T and ran-PDPP/TPDalt2T. (i) $\mathrm{Pd}_{2} \mathrm{dba}_{3},\left(t-\mathrm{Bu}_{3} \mathrm{PH}\left[\mathrm{BF}{ }_{4}\right], \mathrm{K}_{3} \mathrm{PO} \mathrm{O}_{4}, \mathrm{THF} / \mathrm{H}_{2} \mathrm{O}, 80{ }^{\circ} \mathrm{C}\right.$; (ii) $\mathrm{Ni}(\mathrm{cod})_{2}$, bipyridine, toluene, $80{ }^{\circ} \mathrm{C}$. 
Table 1 Molecular Weight, Optical Absorption, and Redox Potentials

\begin{tabular}{llll}
\hline & reg-PDPP/TPDalt2T & ran-PDPP/TPDalt2T & PDPP2T $^{b}$ \\
\hline$M_{\mathrm{n}}\left(\mathrm{kg} \mathrm{mol}^{-1}\right)$ & 50.0 & 34.6 & 85 \\
$M_{\mathrm{w}}\left(\mathrm{kg} \mathrm{mol}^{-1}\right)$ & 137 & 116 & 322 \\
$\mathrm{PDI}$ & 2.74 & 3.36 & 3.8 \\
$\lambda_{\max }(\mathrm{nm})$ & 787 & 768 & 927 \\
$E_{\mathrm{g}}^{\text {sol }}(\mathrm{eV})$ & 1.43 & 1.30 & 1.25 \\
$E_{\mathrm{g}}(\mathrm{eV})$ & 1.42 & 1.29 & 1.20 \\
$E_{\mathrm{Ox}}(\mathrm{V})^{a}$ & 0.55 & 0.48 & 0.53 \\
$E_{\mathrm{red}}(\mathrm{V})^{a}$ & -1.39 & -1.29 & -1.19 \\
$E(\mathrm{HOMO})(\mathrm{eV})^{c}$ & -5.78 & -5.71 & -5.76 \\
$E(\mathrm{LUMO})(\mathrm{eV})^{c}$ & -3.84 & -3.94 & -4.04 \\
${ }^{a}$ Versus Fc/Fc & ${ }^{b}$ Values from ref. & $29 .{ }^{c}$ Determined using a work- \\
function value of $-5.23 \mathrm{eV}$ for Fc/Fc ${ }^{+}$. &
\end{tabular}

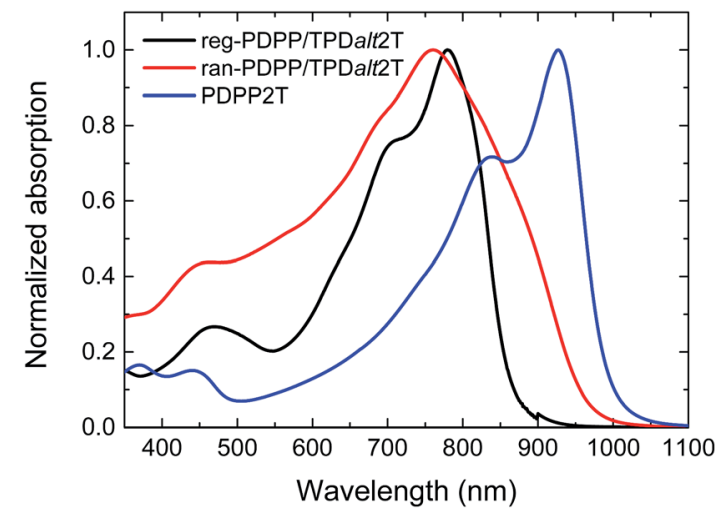

Fig. 1 UV/vis/NIR absorption spectra of reg-PDPP/TPDalt2T, ranPDPP/TPDalt2T and PDPP2T in o-DCB solution.

terpolymer and thus a broadened absorption. The features at lower wavelengths are assigned to TPD2T rich sections, based on the absorption spectrum of PTPD2T with additional side chains published by Jo et al., which show a wide band gap of $\sim 1.8 \mathrm{eV}$ and $\lambda_{\max }$ of $570 \mathrm{~nm} .{ }^{30}$ The broadening towards higher wavelengths is attributed to DPP2T enriched segments based on the spectrum of the PDPP2T copolymer, which displays a small band gap with an onset at $\sim 1000 \mathrm{~nm}$. We note that the optical band gap of the random PDPP/TPDalt2T terpolymer is larger than that of PDPP2T. This implies that segments of pure alternating DPP2T are not very long.

To exclude the possibility that the spectral broadening is due to aggregation of polymer chains, we measured the temperature dependence in $o$-DCB solution and found that, apart from a small blue shift of the onset of absorption, the broadening is largely retained at $100{ }^{\circ} \mathrm{C}$ (ESI, Fig. S3†). For the regular PDPP/ TPDalt2T the entire spectrum shifts hypsochromically with increasing temperature, while the low-energy shoulder at 820 $\mathrm{nm}$ slowly disappears suggesting that polymer aggregates dissolve (ESI, Fig. S3†).

Frontier orbital energy levels of the polymers estimated by cyclic voltammetry (CV) on solid films (Table 1 and ESI Fig. S4†) indicate that the LUMO level of the random terpolymer is in between the LUMO levels of the regular terpolymer and that of
PDPP2T. We infer that the relatively low LUMO energy level of the random polymer compared to the regular material is caused by DPP-rich fragments. The HOMO energy levels of the three polymers are much closer.

To study the effect of the co-monomer sequence on the spatial extension of the frontier orbitals over the conjugated backbone and on the expected energy levels, density functional theory (DFT) calculations were carried out on model oligomers containing four acceptor units (Fig. 2). For the perfectly alternating system (a) and the sequence with two TPD units in the center (b), both HOMO and LUMO are fully delocalized and the calculated energy levels show relative deep HOMO and high LUMO energy levels. In sharp contrast, for systems where two DPP units are adjacent (systems (c) and (d)), both the HOMO and the LUMO are significantly more localized on the DPP-rich segments. Moreover, higher HOMO and lower LUMO energy levels are calculated, causing a decrease in band gap when compared to systems (a) and (b). This suggests that in the random terpolymer, DPP2T rich domains will result in a localization of the frontier orbitals and a local lowering of the optical band gap compared to the regular copolymer. This tendency is consistent with the red shift of optical absorption spectra (Fig. 1) and the lowering of LUMO and increase in HOMO (Table 1) for the random terpolymer compared to the regular terpolymer. We note, however, that the HOMO level op PDPP2T is not really increased compared to reg-PDPP/TPDalt2T and actually somewhat lower than that of ran-PDPP/TPDalt2T, even though its band gap and LUMO level are reduced.

Bulk heterojunction photovoltaic devices of the terpolymers were made with [6,6]-phenyl- $\mathrm{C}_{71}$-butyric acid methyl ester ([70] PCBM) as acceptor. The active layer was sandwiched between a transparent ITO/PEDOT:PSS front electrode and reflective $\mathrm{LiF} /$ Al metal back electrode. The photoactive layers were carefully optimized in terms of thickness, polymer-fullerene ratio, and solvent composition of the spin coating solution. Both materials had identical optimized processing conditions and displayed the highest performance when spin coated from a chloroform solution containing 2 vol\% diiodooctane as cosolvent and using a $1: 2$ polymer-fullerene ratio. The $J-V$ curves of cells based on the random and regular terpolymers are shown in Fig. 3 and their characteristics summarized in Table 2. The open-circuit voltage $\left(V_{\text {oc }}\right)$ for the cell with the random terpolymer at $0.74 \mathrm{~V}$ is $40 \mathrm{mV}$ lower than that of the regular terpolymer. As the $V_{\text {oc }}$ is related to the $\mathrm{HOMO}_{\text {donor }}-$ LUMO $_{\text {acceptor }}$ energy offset, this is in line with the differences in HOMO energy levels between the polymers (Table 1). There is a small difference in fill factor (FF), favoring the reg-PDPP/ TPDalt2T:[70]PCBM cell. The most striking difference, however, is found in the short-circuit current $\left(J_{\mathrm{sc}}\right)$ were the regular terpolymer produces over four times the photocurrent compared to the random terpolymer. A closer look at the external quantum efficiency (EQE) spectra reveals that the regPDPP/TPDalt2T:[70]PCBM cell has an equally strong response in the [70]PCBM absorption range (350-650 nm) and the polymer absorption range (650-900 nm). In contrast, the ran-PDPP/ TPDalt2T:[70]PCBM cell shows a negligible contribution in the polymer absorption range and a small response for [70]PCBM. 
(a)

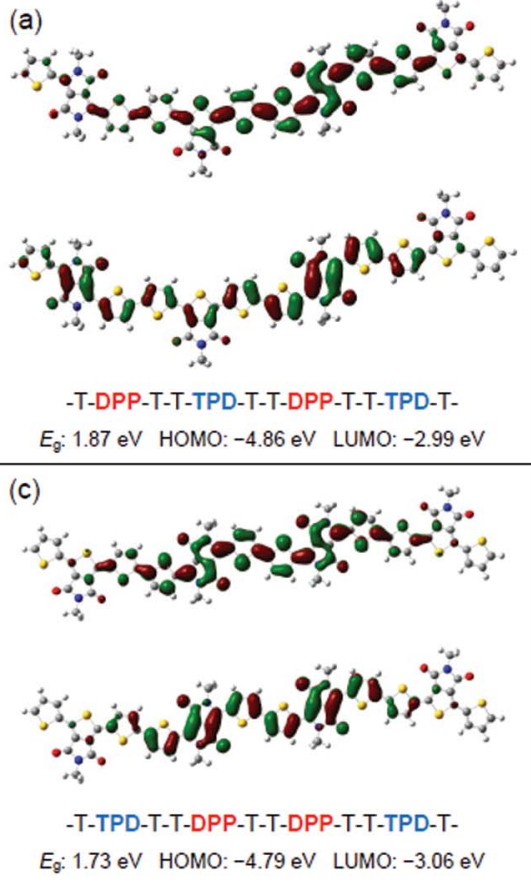

(b)
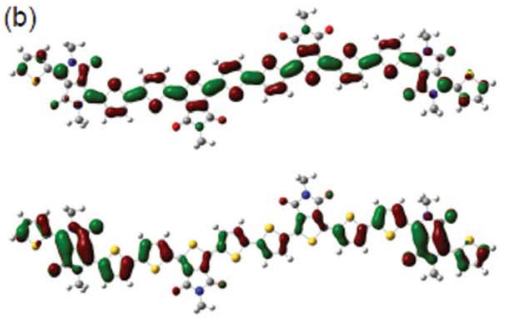

-T-DPP-T-T-TPD-T-T-TPD-T-T-DPP-T$E_{\mathrm{g}}: 2.00 \mathrm{eV}$ HOMO: $-4.91 \mathrm{eV}$ LUMO: $-2.91 \mathrm{eV}$

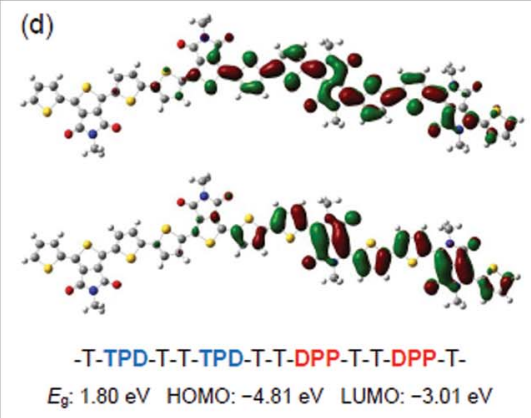

Fig. 2 Spatial distribution of the HOMO (below) and LUMO (top) orbitals on four repeat unit model systems calculated by DFT modeling at the DFT/B3LYP 6-31G(d) level. Alkyl chains have been simplified to methyl groups.

The imbalance in the contributions to the EQE of the latter cell is not caused by a poor absorption of light by the polymer (ESI, Fig. $\mathrm{S} 5 \dagger$ ). We attribute this rather to the reduced $\mathrm{LUMO}_{\text {donor }}-$ $\mathrm{LUMO}_{\text {acceptor }}$ energy offset for the random terpolymer and the fullerene. When the photon energy loss is evaluated for both polymers (as determined by $E_{\mathrm{g}}-e V_{\mathrm{oc}}$, where $E_{\mathrm{g}}$ is the optical band gap and $e$ the elementary charge) values of $0.55 \mathrm{eV}$ for the random and $0.64 \mathrm{eV}$ for the regular terpolymer are found. $\mathrm{A}$ minimum photon energy loss of $\sim 0.6 \mathrm{eV}$ has previously been proposed as a lower threshold to provide sufficient energy for charge separation..$^{31}$ Because the random polymer is below this limit, the photon energy loss can explain the difference in current generation between the polymers. In fact, the $\mathrm{EQE}$ for the random polymer is virtually identical to that of PDPP2T:[70] PCBM, for which it has been shown earlier that the $\mathrm{LUMO}_{\text {donor }}$ - $\mathrm{LUMO}_{\text {acceptor }}$ offset is insufficient to afford any current generation from the polymer excited state. ${ }^{29}$ The results demonstrate that DPP2T-rich segments along the random terpolymer chain have an equally detrimental effect on the efficiency of the devices. The photocurrent created in the 350$650 \mathrm{~nm}$ spectral region in ran-PDPP/TPDalt2T:[70]PCBM and PDPP2T:[70]PCBM cells most likely originates from hole transfer of excitons generated in the fullerene domains to the polymer. Overall the power conversion efficiency (PCE) of the random terpolymer merely reaches $1.0 \%$, while a more favorable $5.3 \%$ is obtained for the regular terpolymer.

The morphology of the active layers was investigated with TEM and AFM. The results are shown in Fig. 4 and S6 (ESI $\dagger$ ). In bright-field TEM the darker features result from [70]PCBM because of its higher density. Clearly the optimized blends have distinctly different morphologies. The regular terpolymer shows a finely dispersed morphology with fiber-like polymer-rich
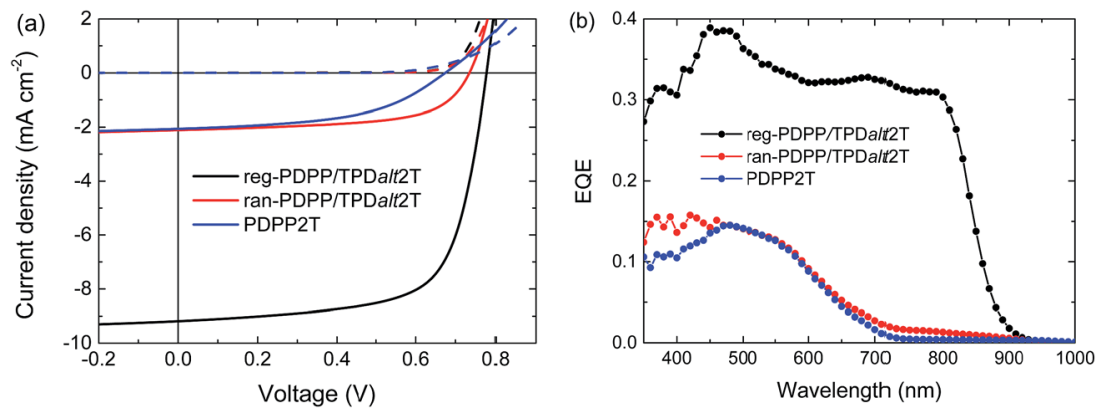

Fig. 3 (a) J-V curves of solar cells of reg-PDPP/TPDalt2T:[70]PCBM, ran-PDPP/TPDalt2T:[70]PCBM, and PDPP2T:[70]PCBM. (b) The corresponding EQE spectra. 
Table 2 Solar Cell Characteristics for DPP-TPD-2T Terpolymers

\begin{tabular}{|c|c|c|c|c|c|c|}
\hline Polymer & $d(\mathrm{~nm})$ & $V_{\mathrm{oc}}(\mathrm{V})$ & $J_{\mathrm{sc}}{ }^{a}\left(\mathrm{~mA} \mathrm{~cm}^{-2}\right)$ & $\mathrm{FF}$ & $E_{\mathrm{g}}-e V_{\mathrm{oc}}(\mathrm{eV})$ & PCE (\%) \\
\hline reg-PDPP/TPDalt2T & 108 & $0.78(0.78)$ & $9.95(9.60)$ & $0.68(0.68)$ & 0.64 & $5.3(5.1)$ \\
\hline ran-PDPP/TPDalt2T & 108 & $0.74(0.73)$ & $2.31(2.13)$ & $0.61(0.59)$ & 0.55 & $1.0(0.9)$ \\
\hline
\end{tabular}

${ }^{a}$ Determined by integrating the EQE spectrum with the AM1.5G spectrum. The values in brackets are average values of 8 nominally identical devices.
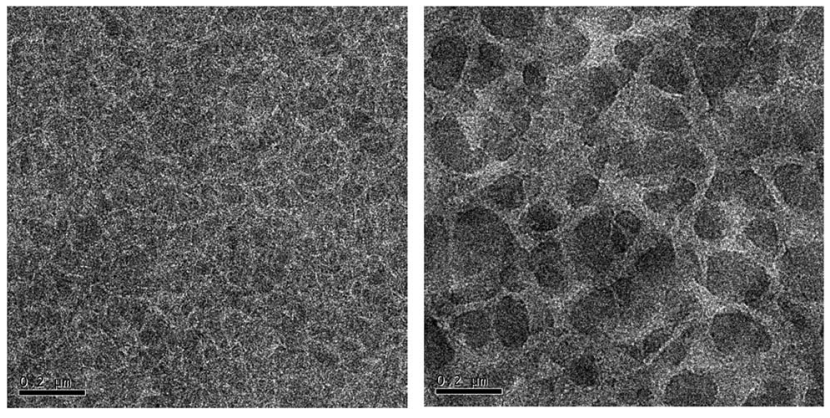

Fig. 4 Bright-field TEM images of active layers from reg-PDPP/ TPDalt2T and ran-PDPP/TPDalt2T with [70]PCBM. The scale bar is $200 \mathrm{~nm}$.

structures that are in general beneficial for efficient exciton dissociation. The random terpolymer shows a much coarser morphology and rougher surface. The differences in morphology can either be caused by the difference in molecular weight $\left(M_{\mathrm{n}}=50.0 \mathrm{~kg} \mathrm{~mol}^{-1}\right.$ vs. $\left.M_{\mathrm{n}}=34.6 \mathrm{~kg} \mathrm{~mol}^{-1}\right)$ or by the different sequential distribution of monomeric units and associated solubilizing alkyl chains along the chain of the regular and random terpolymers.

It is clear that in addition to the insufficient $\mathrm{LUMO}_{\text {donor }}-$ LUMO $_{\text {accpetor }}$ energy offset caused by DPP2T-rich segments, the coarse phase separation of the random terpolymer blend can also limit the photocurrent. Although the feature size of the terpolymer domains is larger than the typical exciton diffusion length in semiconducting polymers of $5-10 \mathrm{~nm}$, this would not reduce charge generation when a small amount of [70]PCBM is present in such domain. However, electrons that would be generated within such polymer-rich phase are difficult to collect when there are insufficient percolating pathways of [70]PCBM. ${ }^{32}$ This effect, however, would result in a photocurrent that strongly depends on the voltage bias (to extract the electrons) and would continue to increase under reverse bias conditions. ${ }^{32}$ This is not observed in the ran-PDPP/TPDalt2T:[70]PCBM devices. Hence, the fact that absorption of light by ran-PDPP/ TPDalt2T does not contribute to the photocurrent is primarily caused by its low lying and localized LUMO level that hampers electron transfer to [70]PCBM.

\section{Conclusions}

Regular PDPP/TPDalt2T and random PDPP/TPDalt2T terpolymers were synthesized. Experimental results and DFT calculations reveal that DPP2T-rich sections in the random terpolymer cause a localization of the frontier orbitals in these segments with a concomitant rise of the HOMO and lowering of the LUMO energy levels. This results in a smaller optical band gap of the random terpolymer compared to the regular terpolymer. The simultaneous presence of TPD2T-rich segments also broadens the absorption spectrum of the random terpolymer to higher energies. The higher HOMO level reduces the open circuit voltage in solar cells with [70]PCBM, while the low lying LUMO energy level hampers exciton dissociation in solar cells and results in a significant reduction of the photocurrent and efficiency of ran-PDPP/TPDalt2T:[70]PCBM (PCE $=1.0 \%)$ when compared to reg-PDPPaltTPD2T:[70]PCBM (PCE $=5.3 \%)$ solar cells. The study clearly shows that when designing new terpolymers for photovoltaic applications, it is important to consider the electronic nature of all segments that can be formed. For random terpolymers the broadening of the energy levels caused by the statistical distribution of electronically different units can increase the wavelength range for absorption of light and improve the performance. ${ }^{13,14,24}$ But, as shown here, any segments that lead to deep lying LUMO or high lying HOMO levels should be avoided in order to maximize the photovoltaic performance of the polymer.

\section{Experimental section}

The detailed synthesis of the monomers and polymers are described in the ESI. $\uparrow$ Molecular weight distributions of the polymers were estimated by GPC at $80{ }^{\circ} \mathrm{C}$ on a PL-GPC 120 system using a PL-GEL $10 \mu \mathrm{m}$ MIXED-B column with $o$-DCB as the eluent and using polystyrene internal standards. UV/vis/NIR spectroscopy was conducted on a Perkin Elmer Lambda 900 spectrophotometer. Cyclic voltammetry was performed under an inert atmosphere with a scan speed of $0.1 \mathrm{~V} \mathrm{~s}^{-1}$ in an acetonitrile solution of $1 \mathrm{M}$ tetrabutylammonium hexafluorophosphate. An ITO glass slide covered with a thin layer of polymer (approx. $20 \mathrm{~nm}$ ) was used as working electrode, a silver rod as counter electrode and silver rod coated with silver chloride $(\mathrm{Ag} / \mathrm{AgCl})$ as quasi-reference electrode in combination with $\mathrm{Fc} / \mathrm{Fc}^{+}$as an internal standard. Atomic force microscopy (AFM) was measured on an extended Veeco MultiMode AFM connected to a Nanoscope III controller in tapping mode using PPPNCH-50 probes (Nanosensors). TEM was performed on a Tecnai $\mathrm{G}^{2}$ Sphera TEM (FEI) operated at $20 \mathrm{kV}$.

Photovoltaic devices with an active area of 0.09 and $0.16 \mathrm{~cm}^{2}$ were fabricated by spin coating poly(ethylenedioxy thiophene):poly(styrenesulfonate) (PEDOT:PSS) (Clevios P, VP Al4083) on pre-cleaned, patterned indium tin oxide (ITO) glass 
substrates (Naranjo Substrates). Solutions contained $6 \mathrm{mg} \mathrm{mL}^{-1}$ polymer and $12 \mathrm{mg} \mathrm{mL}^{-1}$ [70]PCBM (90-95\% Solenne BV) with 2 vol\% diiodooctane in chloroform, and were spin coated at spin speeds between 1000 and $2000 \mathrm{rpm}$. The back electrode consisted of $\mathrm{LiF}(1 \mathrm{~nm})$ and $\mathrm{Al}(100 \mathrm{~nm})$ which were deposited by evaporation under high vacuum $\left(\sim 3 \times 10^{-7}\right.$ mbar $) . J-V$ characteristics were measured with a Keithley 2400 source meter under $\sim 100 \mathrm{~mW} \mathrm{~cm}^{-2}$ white light illumination from a tungstenhalogen lamp filtered by a Schott GG385 UV filter and a Hoya LB120 daylight filter. Short-circuit currents under AM1.5G conditions were estimated by convoluting the spectral response with the solar spectrum. Spectral response measurements were conducted under 1 sun operating conditions by using a $532 \mathrm{~nm}$ solid state laser (Edmund Optics) for bias illumination. The device was kept in a nitrogen filled box behind a quartz window and irradiated with modulated monochromatic light, from a $50 \mathrm{~W}$ tungsten-halogen lamp (Philips focusline) and monochromator (Oriel, Cornerstone 130) with the use of a mechanical chopper. The response was recorded as a voltage over a $50 \Omega$ resistor using a lock-in amplifier (Stanford research Systems SR830). A calibrated silicon cell was used as reference. The thickness of the active layers was determined on a Veeco Dektak150 profilometer.

For the DFT (density functional theory) modeling, structures were generated using Gaussview 3.0 and optimized to a minimum using the Gaussian 03 program. ${ }^{33}$ The Becke three parameter hybrid functionals Lee-Yang-Parr (B3LYP) $)^{34,35}$ level of theory was employed using the standard 6-31G(d) basis set.

\section{Acknowledgements}

The work was supported by the "Europees Fonds voor Regionale Ontwikkeling" (EFRO) in the Interreg IV-A project Organext. The research forms part of the Solliance OPV program and has received funding from the Ministry of Education, Culture and Science (Gravity program 024.001.035).

\section{Notes and references}

1 Y. Li, P. Sonar, L. Murphy and W. Honga, Energy Environ. Sci., 2013, 6, 1684.

2 K. H. Hendriks, G. H. L. Heintges, V. S. Gevaerts, M. M. Wienk and R. A. J. Janssen, Angew. Chem., Int. Ed., 2013, 52, 8341.

3 H. Bronstein, Z. Chen, R. S. Ashraf, W. Zhang, J. Du, J. R. Durrant, P. S. Tuladhar, K. Song, S. E. Watkins, Y. Geerts, M. M. Wienk, R. A. J. Janssen, T. Anthopoulos, H. Sirringhaus, M. Heeney and I. McCulloch, J. Am. Chem. Soc., 2011, 133, 3272.

4 L. Dou, H.-H. Chang, J. Gao, C.-C. Chen, J. Jou and Y. Yang, Adv. Mater., 2013, 25, 825.

5 A. T. Yiu, P. M. Beaujuge, O. P. Lee, C. H. Woo, M. F. Toney and J. M. J. Fréchet, J. Am. Chem. Soc., 2012, 134, 2180.

6 L. Ye, S. Zhang, W. Ma, B. Fan, X. Guo, Y. Huang, H. Ade and J. Hou, Adv. Mater., 2012, 24, 6335.
7 C. Cabanetos, A. E. Labban, J. A. Bartelt, J. D. Douglas, W. R. Mateker, J. M. J. Fréchet, M. D. McGehee and P. M. Beaujuge, J. Am. Chem. Soc., 2013, 135, 4656.

8 C. E. Small, S. Chen, J. Subbiah, C. M. Amb, S.-W. Tsang, T.-H. Lai, J. R. Reynolds and F. So, Nat. Photonics, 2012, 6, 115.

9 X. Guo, R. P. Ortiz, Y. Zheng, M.-G. Kim, S. Zhang, Y. Hu, G. Lu, A. Facchetti and T. J. Marks, J. Am. Chem. Soc., 2011, 133, 13685.

10 T.-Y. Chu, J. Lu, S. Beaupré, Y. Zhang, J.-R. Pouliot, S. Wakim, J. Zhou, M. Leclerc, Z. Li, J. Ding and Y. Tao, J. Am. Chem. Soc., 2011, 133, 4250.

11 J. W. Jung, F. Liu, T. P. Russell and W. H. Jo, Energy Environ. Sci., 2013, 6, 3301.

12 X. Hu, W. Fu, L. Zuo, H. Shi, M. Chen, S. Liu, J. Pan, L. Fu, M. Shi and H. Chen, Tetrahedron, 2013, 69, 3419.

13 B. Burkhart, P. P. Khlyabich and B. C. Thompson, ACS Macro Lett., 2012, 1, 660.

14 T. E. Kang, H.-H. Cho, H. J. Kim, W. Lee, H. Kang and B. J. Kim, Macromolecules, 2013, 46, 6806.

15 T. E. Kang, K.-H. Kim and B. J. Kim, J. Mater. Chem. A, 2014, 2, 15252.

16 M. Zhang, F. Wu, Z. Cao, T. Shen, H. Chen, X. Lia and S. Tan, Polym. Chem., 2014, 5, 4054.

17 P. P. Khlyabich, B. Burkhart, C. F. Ng and B. C. Thompson, Macromolecules, 2011, 44, 5079.

18 L. Fang, Y. Zhou, Y.-X. Yao, Y. Diao, W.-Y. Lee, A. L. Appleton, R. Allen, J. Reinspach, S. C. B. Mannsfeld and Z. Bao, Chem. Mater., 2013, 25, 4874.

19 W.-H. Chang, J. Gao, L. Dou, C.-C. Chen, Y. Liu and Y. Yang, Adv. Energy Mater., 2014, 4, 1300864.

20 C. H. Chen, Y. J. Cheng, C. Y. Chang and C. S. Hsu, Macromolecules, 2011, 44, 8415.

$21 \mathrm{~J}$. Zhou, S. Xie, E. F. Amond and M. L. Becker, Macromolecules, 2013, 46, 3391.

22 J. Li, K. H. Ong, P. Sonar, S. L. Lim, G. M. Ng, H. K. Wong, H. S. Tan and Z. K. Chen, Polym. Chem., 2013, 4, 804.

23 Y. Lim, S. G. Ihn, X. Bulliard, S. Yun, Y. Chung, Y. Kim, H. Chang and Y. S. Choi, Polymer, 2012, 53, 5275.

24 C. B. Nielsen, R. Shahid Ashraf, B. C. Schroeder, P. D'Angelo, S. E. Watkins, K. Song, T. D. Anthopoulos and I. McCulloch, Chem. Commun., 2012, 48, 5832.

25 T. Qin, W. Zajaczkowski, W. Pisula, M. Baumgarten, M. Chen, M. Gao, G. Wilson, C. D. Easton, K. Mullen and S. E. Watkins, J. Am. Chem. Soc., 2014, 136, 6049.

26 W. Sun, Z. Ma, D. Dang, W. Zhu, M. R. Andersson, F. Zhang and E. Wang, J. Mater. Chem. A, 2013, 1, 11141.

27 Z. Deng, L. Chen and Y. Chen, J. Polym. Sci., Part A: Polym. Chem., 2013, 51, 4885.

28 W. A. Braunecker, S. D. Oosterhout, Z. R. Owczarczyk, N. Kopidakis, E. L. Ratcliff, D. S. Ginley and D. C. Olson, ACS Macro Lett., 2014, 3, 622.

29 A. P. Zoombelt, S. G. J. Mathijssen, M. G. R. Turbiez, M. M. Wienk and R. A. J. Janssen, J. Mater. Chem., 2010, 20, 2240. 
30 J. Jo, A. Pron, P. Berrouard, W. L. Leong, J. D. Yuen, J. S. Moon, M. Leclerc and A. J. Heeger, Adv. Energy Mater., 2012, 2, 1397.

31 D. Veldman, S. C. J. Meskers and R. A. J. Janssen, Adv. Funct. Mater., 2009, 19, 1939.

32 S. Kouijzer, J. J. Michels, M. van den Berg, V. S. Gevaerts, M. Turbiez, M. M. Wienk and R. A. J. Janssen, J. Am. Chem. Soc., 2013, 135, 12057.
33 M. J. Frisch, et al., GAUSSIAN 03 (Revision B.04), Gaussian Inc., Pittsburgh, PA, 2003.

34 A. D. Becke, J. Chem. Phys., 1993, 98, 5648.

35 P. J. Stephens, F. J. Devlin, C. F. Chabalowski and M. J. Frisch, J. Phys. Chem., 1994, 98, 11623. 